\title{
Experiências de parentalidade como fatores geradores de sofrimento em mulheres
}

\author{
Fabiola Langaro, Zuleica Pretto ${ }^{\star}$ \\ Universidade Federal de Santa Catarina
}

\begin{abstract}
Resumo
Durante o trabalho realizado por meio de um Projeto de Extensão em Saúde Mental na Grande Florianópolis, percebeu-se que o relato de sofrimento das mulheres participantes estava relacionado às suas experiências de maternidade e paternidade. A partir desta problemática, foi realizada uma pesquisa com o objetivo de compreender de que forma as experiências de parentalidade estavam se constituindo em fatores geradores de sofrimento naquelas mulheres. Para tanto, realizaram-se cinco entrevistas individuais e um grupo focal. Os dados coletados foram discutidos em quatro categorias de análise, tendo sido destacado que o sofrimento das participantes estava relacionado principalmente à vivência da parentalidade a partir de modelos tradicionais de gênero, caracterizados pela centralidade do perfil de mãe; às diferenças na responsabilidade pela educação dos filhos/filhas, assumida por homens e mulheres; à idade dos filhos/filhas e, finalmente, à vivência de dúvidas e incertezas que nem sempre podem ser mediadas em seu cotidiano.
\end{abstract}

Palavras-chave: maternidade; paternidade; parentalidade; mulheres; sofrimento.

\section{Experiences of parenthood as generating factors of suffering in women}

\begin{abstract}
During the work accomplished through an Extension Project in Mental Health in the Great Florianópolis, it was noticed that the suffering report of the participant women was mainly related to their experiences of motherhood and fatherhood. Considering this, a research was developed, which aimed to understand the ways their parenthood experiences were becoming generating factors of suffering in those women. To achieve that, five individual interviews and a focal group took place. The data collected was discussed through four analysis categories, in which it was highlighted that their suffering was mainly due to the experiences of parenthood from traditional models of gender, characterized for the main place of the mother, to the differences in the responsibility for the children education assumed by men and women, to the children's age and, finally, to the experiences of uncertainties that not always can be mediated in their everyday life.
\end{abstract}

Keywords: motherhood; fatherhood; women; parenthood; suffering.

\section{Trajetórias da pesquisa}

Pelo período de dois anos, grupos de reflexão com homens e mulheres foram organizados por intermédio de um Projeto de Extensão em Saúde Mental, realizado em um serviço de saúde do SUS, na Grande Florianópolis - SC, desenvolvido pelo curso de Psicologia da Universidade do Vale do Itajaí. O trabalho, na forma de grupos de reflexão, contava com encontros semanais com duração de 1h30min. Coordenavam o grupo uma psicóloga e duas bolsistas extensionistas do curso de Psicologia, entre elas a pesquisadora, a partir de uma perspectiva que visava criar espaços de autonomia e autogestão, auxiliando as pessoas a assumirem a responsabilidade sobre a sua saúde mediante uma abordagem ampliada do processo saúde e doença. As atividades, de cunho educacional, objetivavam promover a saúde e a qualidade de vida de pessoas atendidas por oito centros de saúde, por apresentarem queixas relacionadas a experiências de sofrimento mental.

O caráter de extensão deste projeto chama a atenção para a forma como a atuação da Psicologia nos espaços de saúde pública tem sido organizada no Brasil. Conforme destaca Kahhale (2003), a inserção do psicólogo nos serviços públicos de saúde brasileiros foi impulsionada por

\footnotetext{
„Endereço para correspondência: Universidade Federal de Santa Catarina Centro de Filosofia e Ciências Humanas - Programa de Pós-Graduação em Psicologia. Campus Universitário - Trindade - Florianópolis - SC. CEP: 88040 500.E-mail: flangaro@hotmail.com, zuleicapretto@yahoo.com.br
}

um movimento no interior da própria Psicologia, com o desenvolvimento da psicologia social comunitária e, concomitantemente, pelo movimento sanitarista da década de 1980 - que reivindicava por um conceito ampliado de saúde e pela responsabilização do Estado em garantir o acesso da população a estes serviços, tendo culminado com a implantação do Sistema Único de Saúde (SUS).

Desde então, percebe-se uma crescente preocupação em oferecer, nestes espaços, atendimento integral aos sujeitos, abrangendo seus aspectos biológicos, psíquicos e sociais, conforme preconizado pelo SUS. Contudo, a realidade brasileira é a de poucos locais de atendimento psicológico gratuito disponíveis para as camadas populares, haja vista que as equipes de unidades básicas e demais serviços públicos de saúde nem sempre são contemplados com profissionais da psicologia.

Como exemplo desta lacuna, destaca-se a ausência de psicólogos nas equipes básicas do Programa de Saúde da Família. Neste sentido, o desenvolvimento das atividades em psicologia, por intermédio do Projeto de Extensão em Saúde Mental, caracterizou-se como uma tentativa de "compreender as relações sociais e as formas de produção da vida como fatores responsáveis pela produção do mundo psicológico" (BOCK, 2003, p. 27), visando rom- 
per o tradicional compromisso com as classes dominantes, fato que marcou a trajetória da psicologia desde sua regulamentação como profissão no Brasil.

Ressalta-se que durante a realização das atividades num grupo de reflexão do referido projeto, as mulheres participantes queixavam-se fundamentalmente de depressão e ansiedade. Além disso, quando faziam menção às suas histórias de vida, relatavam terem anulado suas vontades, anseios e sonhos para cuidar das pessoas relacionadas ao convívio familiar, tendo estas experiências acarretado um estado de sofrimento que as levou a procurar ajuda psicológica. Referiam-se a angústia gerada pelas vivências de maternidade e paternidade experimentadas em suas vidas, caracterizadas, principalmente, pela falta de reciprocidade na entrega e na dedicação ao outro e no não-reconhecimento de seus esforços pela organização e manutenção da vida familiar.

Dessa forma, era possível compreender, sob a ótica da psicologia existencialista sartreana, que o sofrimento daquelas mulheres, naquele momento, aparecia como ligado às relações que estabeleciam em suas experiências cotidianas no âmbito familiar. Isto porque, segundo Sartre (1978a), o sujeito se constitui enquanto subjetividade única - emocionando-se, pensando e agindo de maneira particular - nas relações estabelecidas com a exterioridade. Isto é, a estrutura social em que está inserido fornece o horizonte no qual encontrará os parâmetros para construir sua singularidade, apropriando-se ativamente desse conjunto de práticas sociais, valores, conhecimentos, ideologias, afetividades, histórica e culturalmente constituídas.

Destaca-se que neste processo de construção de sua subjetividade, em que se apropria da realidade e age fazendo escolhas, é possível que o sujeito relacione-se com os objetos a partir de uma consciência espontânea ou de uma consciência crítica. A primeira delas é não-posicional de si, ou seja, é uma consciência espontânea/alienada no objeto, em que o sujeito não toma a si mesmo como objeto de consciência e não se questiona sobre suas experiências, mas as aceita como verdades absolutas. Já no segundo modo de posicionamento, o sujeito passa a ser, ele mesmo, objeto de sua consciência, saindo da consciência espontânea e passando para uma consciência que é reflexiva crítica (SARTRE, 1978b).

Assim, tendo em vista as problemáticas apresentadas pelas mulheres no grupo de reflexão, e as possibilidades de entendimento dos fenômenos psicológicos proporcionados pela teoria existencialista (SARTRE, 1978a, 1978b; BEAUVOIR, 1949, 1980; SCHNEIDER, 2006, 2011; PRETTO, 2003; MAHEIRIE; PRETTO, 2007) e por estudos de gênero (SAFFIOTI, 1987; SCOTT, 1990; LOURO, 1998; TONELI, 2006), foi realizada uma pesquisa com o objetivo de compreender a forma como as experiências de parentalidade ${ }^{1}$ se constituíam como fatores geradores de sofrimento para àquelas mulheres. Para

\footnotetext{
Entende-se que a experiência de maternidade traz no seu bojo a experiência de paternidade, ou seja, que o "ser mãe" das mulheres está atravessado pelo modo como seu parceiro exerce a paternidade. Dessa forma, a vivência que a mulher tem da paternidade em seu cotidiano implicará no seu próprio modo de vivenciar a maternidade. Portanto, por compreender que estes são aspectos de um mesmo fenômeno e, por isso, indissociáveis, optou-se por manter o termo parentalidade na pesquisa.
}

alcançar este objetivo, foram investigadas as experiências do cotidiano das mulheres em relação à vivência da maternidade e da paternidade, abarcando as principais dificuldades encontradas nestas relações, seu entendimento sobre o que é ser mãe e ser pai e, ainda, como elas estabeleciam alguma relação entre maternidade e paternidade e o seu sofrimento.

\section{Constituição do sujeito e gênero}

Para a teoria existencialista sartreana, o homem é entendido como corpo e consciência no mundo. O corpo lhe garante estar em situações existenciais historicamente determinadas e a consciência lhe confere a característica relacional, obrigando-o a posicionar-se diante de cada objeto, pessoa, situação com a qual se relaciona. Ou seja, sua dimensão subjetiva não é determinada a priori, mas “dirige-se para um futuro aberto onde irá constituir-se conforme as condições existenciais que vivencia e é capaz de criar" (PRETTO, 2003, p. 16).

Sendo a liberdade constitutiva do ser, o sujeito será constantemente lançado à necessidade de realizar escolhas, que estão sempre relacionadas a um projeto, um desejo de ser. Suas escolhas cotidianas se relacionam a uma escolha essencial, que os leva a um projeto fundamental, caracterizado pela totalização em curso, que é o homem (SCHNEIDER, 2011). Suas escolhas serão feitas, contudo, na realidade antropológica e sociológica em que estiver inserido, o que faz com que o sujeito só possa ser compreendido levando-se em consideração sua história individual implicada por um contexto. É no estabelecimento das relações com o outro, que irá mediar suas relações com as coisas, com o tempo e com seu próprio corpo, que o sujeito terá possibilidades de construir sua personalidade. Portanto, o tecido sociológico implica numa rede de relações de mediações que fornece os parâmetros para a construção da singularidade do sujeito, resultando em sua dimensão psicológica (SCHNEIDER, 2006; 2011).

Segundo Sartre (1978b), é no processo de apropriação de sua situação - de suas condições materiais, sociais, familiares e existenciais concretas - que o sujeito irá constituir sua subjetividade, verificada em seu processo de objetivação, através de sua ação, pensamentos e emoções. Portanto, a personalidade do sujeito se constitui a partir da contínua subjetivação da objetividade e da objetivação da subjetividade, ou seja, da ação de interiorização da exterioridade que se consolida como uma subjetividade objetivada.

É a partir do outro - pessoa, objeto, racionalidade, corpo, tempo - que o sujeito apreende significados e sentidos para o mundo e para si e, mais do que isso, é a partir dessa relação que é significado como um ser humano entre outros seres humanos (MAHEIRIE; PRETTO, 2007, p. 458). 
Nesse processo de apropriação da exterioridade, que ocorre influenciada pelas mediações ${ }^{2}$ a que o indivíduo está sujeito, "a organização social das diferenças sexuais e a construção de significados atribuídos às mesmas se concretizam nas relações sociais cotidianas" (SANDRI, 2001, p. 42). Dessa forma, também "a sexualidade não é apenas uma questão pessoal, mas é social e política [em que] a inscrição dos gêneros - feminino ou masculino - nos corpos é feita, sempre, no contexto de uma determinada cultura e, portanto, com as marcas dessa cultura" (LOURO, 1998, p. 11).

Para Joan Scott (1990), a palavra "gênero", como categoria de análise, refere-se à forma como ocorre a organização social da relação entre os sexos, sendo o primeiro campo em que o poder - enquanto controle ou acesso diferencial às fontes materiais e simbólicas - é articulado. Assim, o gênero, como uma dimensão decisiva da organização da igualdade e da desigualdade (SCOTT, 1990) também irá permear as concepções e as vivências de maternidade e paternidade vivenciadas por homens e mulheres. Da mesma forma, estas vivências apresentam-se todo o tempo como transpassadas pelas identidades de gênero construídas por homens e mulheres. Como uma das possibilidades de construção deste entrecorte, Braga e Amazonas (2005, p. 15) descrevem que "historicamente [...] a maternidade alcançou um lugar de sofrimento voluntário e indispensável à constituição da mulher".

Este entrelaçamento da feminilidade à maternidade apontado por Braga e Amazonas (2005), historicamente foi construído e reforçado com o surgimento da família nuclear burguesa. Conforme descreve Ariès (1981), o conceito de família passou por muitas transformações desde o período medieval até adquirir as características identificadas na modernidade, passando por mudanças quanto ao desenvolvimento do sentimento de infância, dos cuidados com as crianças e da relação dos pais com a educação dos filhos. Aparece então o conceito de família nuclear, financiado principalmente pela ascensão da burguesia no século XVIII, a partir da Revolução Industrial iniciada na Europa.

A partir da valorização deste conceito de família, "ocorreram uma série de mudanças que envolveram a questão feminina" (BRAGA; AMAZONAS, 2005, p. 12). Nessa forma de organização familiar, a mãe passou a ocupar um lugar fundamental, iniciando-se aí uma era das provas de amor, através das práticas de amamentação, cuidado, higiene e da presença materna constante. "A dupla identidade característica do feminino - a mulher-mãe - ganhou maior visibilidade e consistência" (BRAGA; AMAZONAS, 2005, p. 12).

No entanto, como cita Ariès (1981, p. 189), no cenário de final do século XIX e início de século XX, nos países que se industrializavam, as dificuldades econômicas, principalmente nas classes trabalhadoras, fizeram com

\footnotetext{
${ }^{2} \mathrm{O}$ conceito de mediação em Sartre está fundamentado no materialismo históricodialético, que compreende o desenvolvimento humano como resultado da atividade do indivíduo sobre seu meio. Desta forma, o homem age sobre as condições materiais e históricas em que está inserido, tornando-se produto e produtor da situação objetiva em que se insere e a partir da qual poderá, posteriormente, superar o que está dado. Para realizar esta atividade, o homem utiliza ferramentas mediadoras, que compõem o conjunto de instrumentos teóricos e práticos que dispõe para alterar sua condição (SARTRE, 1978a).
}

que o trabalho fabril passasse a ser realizado também por mulheres e crianças. Com a saída da mulher para o mercado de trabalho teve início um processo de modificação nas organizações da família, culminando numa diversidade de novos arranjos familiares na atualidade.

Também no século XX, principalmente a partir da década de 1960, os movimentos feministas lutam pela ampliação do leque temático sobre as mulheres nas discussões científicas, pela conquista de novos direitos e questiona o padrão de maternidade vigorado inquestionavelmente até então (RAGO, 1998). No entanto, ao questionar o lugar social ocupado pela mulher, estes movimentos impulsionaram também uma revisão nas concepções de masculinidade e paternidade.

Neste sentido, nas últimas décadas, algumas pesquisas sobre masculinidade e paternidade têm enfatizado como a diversidade das experiências tem marcado estas construções. Estas mudanças nas vivências do "ser pai" se relacionam ao que Toneli (2006) chama de "novas formas de paternidade", em referência a possibilidades relacionadas a uma maior participação dos homens no cotidiano familiar. Entretanto, há evidências de que as construções destas experiências não acontecem sem conflitos, pelo fato de serem, ainda, "transgressões" aos antigos modelos de comportamento individual e familiar (SOARES; CARVALHO, 2003). Da mesma forma, Kerry Daly (1996 apud PICCININI; SILVA, 2007, p. 572) assinala "uma lacuna entre o que os pais pensam [...] e o que efetivamente fazem", pois possivelmente este seja um momento de transição da cultura, no qual novas possibilidades para as relações entre pais e filhos estejam sendo incorporadas, ao mesmo tempo em que permanecem os modelos dessa geração sobre o modo como foram criados por seus próprios pais.

Portanto, ao buscarem construir suas experiências de maternidade e de paternidade de forma diversa àquela do modelo hegemônico/tradicional de gênero, homens e mulheres podem se deparar com diversas contradições e, ainda, com uma escassez de instrumentos e de mediações que viabilizem estas construções, gerando, no cotidiano de suas relações, uma angústia frente à lacuna entre aquilo possível de ser consolidado e o rumo para o qual seus desejos apontam. Foram, portanto, as experiências concretas das mulheres entrevistadas que esta pesquisa visou descrever, a fim de investigar sobre as possíveis relações de suas experiências da parentalidade e de seu sofrimento.

\section{Metodologia}

Para a produção dos dados, foram realizadas entrevistas individuais com cinco mulheres frequentadoras do grupo de reflexão do Projeto de Extensão Saúde Mental, identificadas no texto através da letra "E" e de números de 1 a 5 . O roteiro de entrevista semiestruturada continha oito perguntas, referentes aos cuidados das mulheres com a casa e com os filhos; sobre como seus maridos estavam incluídos naquela rotina; sobre a sua compreensão a respeito que é ser mãe e ser pai; se existia algum lugar ou momento em que tinham oportunidade de conversar sobre essa vivência da maternidade e da paternidade; o motivo 
da procura ou encaminhamento para o grupo; e, finalmente, se acreditavam que o motivo pelo qual participaram do grupo tinha relação com as questões referentes à maternidade e à paternidade e, se sim, em que sentido.

Por meio destas entrevistas, foram produzidos dados e novos questionamentos, que deram base a um roteiro para a realização de um grupo focal, realizado com o objetivo de ampliar as discussões iniciadas por meio das entrevistas. Para a realização do grupo, a pesquisadora propôs questões disparadoras do diálogo: quais eram as expectativas antes de serem mães e como era ser mãe naquele momento; como havia sido a gestação; qual era o significado que o pai tinha na vida dos filhos e quem era o pai na vida deles; como estava organizada, entre elas e o pai dos filhos, a responsabilidade pela educação deles; como era a relação das entrevistadas com os filhos; e, por fim, o que é ser homem e o que é ser mulher.

As entrevistadas tinham entre 34 e 54 anos de idade, sendo que duas eram mães de quatro filhos, outras duas de um casal e outra de um filho. Quatro delas eram casadas e uma era separada do pai de seu filho. Duas eram donas de casa, sendo seus maridos responsáveis pelo sustento financeiro da casa; uma era aposentada, tendo sido escriturária; outra trabalhava como auxiliar de cozinha em um hospital e, finalmente, a quinta entrevistada trabalhava como secretária também em um hospital. Todas elas moravam num mesmo bairro, caracterizado como de classe popular.

O material produzido por meio das entrevistas individuais e do grupo focal foi submetido a análise de conteúdo, com o objetivo de organizar os dados sob pontos comuns para o exercício da reflexão e de construção de conhecimento com base na teoria existencialista sartreana e dos estudos de gênero. Nesta etapa, foram elencadas categorias de análise, o que significou agrupar elementos, idéias ou expressões em torno de conceitos capazes de abranger estes aspectos (PÁDUA, 2005). Essa técnica de análise foi escolhida por possibilitar o trabalho a partir de indicadores que permitem a inferência relativa às condições de produção das informações, tais como variáveis psicossociais, contexto cultural e contexto de produção das falas das entrevistadas, conforme indica Minayo (2008).

\section{Análise dos dados}

As categorias que se seguem foram estabelecidas a partir do agrupamento dos conteúdos produzidos nas entrevistas individuais e no grupo focal e da análise com base na perspectiva do existencialismo sartreano e dos estudos de gênero. Este trabalho, assim como a recorrência de certos temas, foi facilitado pelos roteiros das entrevistas e do grupo focal, organizados de acordo com os objetivos da pesquisa.

\section{Ser mãe/ser pai}

Durante as entrevistas individuais, as mulheres participantes da pesquisa foram diretamente questionadas sobre o que era "ser mãe" e "ser pai". Agrupando as falas representativas deste entendimento, foram evidenciadas concepções que demarcam uma nítida desigualdade entre as experiências da maternidade e da paternidade, sendo que a maternidade, fundamentalmente, aparece relacionada, como destaca Costa $(2002$, p. 4) a "um desejo que sempre existiu, como natural, instintivo, essencial, como a realização de um sonho do passado". Para a primeira entrevistada, "ser mãe é tudo [...] como mulher, é um sonho que toda menina já nasce, ser mãe”, demonstrando uma visão na qual, como cita Beauvoir (1980, p. 248), “é pela maternidade que a mulher realiza integralmente seu destino fisiológico, é a maternidade sua vocação 'natural', porquanto todo o seu organismo se acha voltado para a perpetuação da espécie".

Aparece também como atributo da maternidade, a centralidade que este perfil ${ }^{3}$ adquire na vida destas mulheres e a negação de si em função da priorização do outro. Ou seja, ao tornarem-se mães, a organização de suas vidas (rotinas, preocupações, objetivos, desejos) passou a voltar-se para o outro representado pelos filhos, ao mesmo tempo em que as decisões no presente e sobre seus projetos de futuro cederam espaço para o desejo do outro. Para a primeira entrevistada,

eu acho que, depois que você é mãe, você se divide, você não é mais, como posso falar.. Não é mais só você. Você tem você, mas antes de pensar em você, você está pensando, mesmo que você está ali pensando 'eu vou fazer tal coisa pra mim', mas você não está fazendo só pra você. Você está fazendo pra você e pensando já nele (E1).

Esta mesma entrevistada, no grupo focal relatou que "esqueci de mim pelos filhos". Para a segunda entrevistada, ser mãe "preenche a vida. Eu já passei por situações que consegui suportar, superei, porque pensei no meu filho. Pensei muito nele [...] eu pensava muito nele 'meu Deus, ele é um menino, ele é uma criança, o que vai ser dele?'". Sobre este aspecto, Beauvoir (1980, p. 286) escreve que "é possível que, dedicando-se a esse duplo [o filho] em que se reconhece e se ultrapassa, a mãe acabe por se alienar inteiramente nele; renuncia a seu eu, sua única preocupação é a felicidade da filha”.

Da mesma forma, ser mãe aparece como algo sagrado quando as entrevistadas relatam que "a mãe é o ideal de tudo na vida do ser humano" (E1) e "desde que me conheço por gente, eu sonhei em ser mãe. Eu jamais quero sair desse mundo sem ter gerado um filho. Queria passar pela experiência de ser mãe" (E2). Além disso, ser mãe também é superar qualquer dificuldade, qualquer limite que, em princípio, pensava-se existir. Ao tornar-se mãe, a mulher descobre-se realizando tarefas - e a principal delas é a de dedicar-se ao outro dando prioridade a ele no seu arranjo de investimentos - que antes considerava impossíveis de serem realizadas.

Nas questões que se referiram ao "ser pai", as falas das entrevistadas denunciavam a atribuição de caráter de grande valia da presença da figura paterna na constituição e desenvolvimento de seus filhos e, ao mesmo tempo, questionamentos sobre como esta presença se efetua no cotidiano, de forma concreta. $\mathrm{O}$ que parece existir, na re-

\footnotetext{
${ }^{3}$ Segundo Sartre (1997), o sujeito, enquanto corpo e consciência, se constitui nas relações que estabelece com os diferentes elementos que constituem a exterioridade, sendo que cada um deles vai constituindo os perfis ou perspectivas de seu ser - profissional, amoroso, filial, parental, de amizade, entre outros. O conjunto articulado desses perfis forma a totalidade de um sujeito.
} 
alidade, é uma distância entre o que se fala sobre o "ser pai" da autêntica vivência dessa experiência, o que gera dúvidas quanto à igualdade de assunção da maternidade e da paternidade por mulheres e homens.

Dessa forma, algumas entrevistadas relatam que ser pai

deve ser assim mais ou menos também. Só que eu não sei se o pai tem tanta proximidade com os filhos, que a mãe tem. Porque a mãe também, o filho nasce, ela tem aquela proximidade, já começando pela amamentação. O pai pode estar ali presente, vendo o filho mamar, mas não tem nada a ver, uma mãe e um pai (E1);

eu acho que ser pai é melhor, claro. Não passa pelos sofrimentos físicos de uma gestação, de um parto, só tem prazer. Ser pai é muito mais fácil (E2);

Diante destas respostas, foi possível pensar que, na compreensão destas mulheres, ser pai não é o mesmo que ser mãe. ${ }^{4}$ Ser mãe significa abraçar as responsabilidades com os filhos e as responsabilidades com a casa de uma forma natural. Mesmo quando existe uma tentativa de aproximar as experiências de maternidade às de paternidade, as falas remetem a construções tradicionais assumidas nestas vivências, em que pais e mães organizam diferentes e desiguais formas de participação no desenvolvimento dos filhos. Este aspecto se confirma na fala da quinta entrevistada:

[...] eu posso até ser egoísta nesse lado, mas eu acho que a mulher assume muita responsabilidade. [...] Ou de repente eu assumi tudo sozinha e o pai confia na mãe e já largou mão disso, que eu acho a vida do homem é bem mais light do que a da mulher [...].

Indo mais a fundo nesta desigualdade, a presença do pai chega até mesmo a ser questionada, por uma das entrevistadas, como relevante na participação da criação dos filhos/filhas, através do relato que faz da fala de seu filho. Segundo ela,

já perguntaram para o meu filho sobre isso [sobre o fato de o pai não ter sido presente, desde o seu nascimento, em função do término do relacionamento com a mãe] e ele disse: 'eu olho pra mim e não sei dizer a diferença de um filho criado com um pai de um filho criado sem pai' (E2).

A exclusão do pai da esfera dos cuidados infantis, segundo Toneli (2006, p. 260), está relacionada ao fato de o "cuidar de alguém" ou "de alguma coisa" dentro de suas casas ser naturalizado em muitas culturas como algo exclusivamente feminino, enquanto o masculino relaciona-se à preocupação com a parte pública (dinheiro, carreira profissional). A partir do momento em que a mulher é capaz de prover o sustento do lar, conquistando espaço na vida pública, portanto, a importância da presença do pai na família e na organização do cuidado com os filhos e com a casa passa a ser questionada.

As questões de gênero aparecem, assim, denunciadas nas falas das entrevistadas. Fala-se, em um "ser homem" e "ser mulher" que permeiam a maneira como a maternidade e a paternidade são vividas de forma diferenciada.

\footnotetext{
${ }^{4}$ Importante lembrar aqui que o grupo entrevistado era formado exclusivamente por mulheres e, portanto, estes dados têm relação direta com a característica desta amostra.
}

O sentimento revelado na fala "muito melhor ser pai do que ser mãe" aponta para a construção da diferença entre o feminino e masculino ao vivenciarem a experiência de responsabilizar-se pela casa e pela família.

Dessa forma, compreendendo a existência de uma diferença referenciada pelas entrevistadas entre as experiências de maternidade e paternidade, percebe-se que a tentativa de incorporar novas possibilidades nas vivências de pais e mães pode gerar, na prática, conflitos entre aquilo que se desejaria ser e aquilo que se apresenta como realmente possível de ser construído. Esta constatação denuncia a importância de incorporar, nas ações em saúde, uma compreensão ampliada de sujeito e a busca pelo desenvolvimento de estratégias pessoais e coletivas de enfrentamento das dificuldades, que dêem conta de mediar os sujeitos na totalidade de suas experiências, rumo à concretização das mudanças desejadas.

\section{Espaço público/espaço privado}

$\mathrm{Na}$ investigação sobre como as mulheres entrevistadas organizavam seu cotidiano, abarcando-se a concretude de suas experiências de maternidade e paternidade e o estabelecimento de suas rotinas a partir do comprometimento com a casa e a educação dos filhos, apareceram elementos que puderam ser agrupados de acordo com a antiga/contemporânea classificação dos espaços públicos e privados. Dessa forma, foram encontrados aspectos que se configuram como uma ocupação diferenciada destes espaços, realizada pela mãe e pelo pai. ${ }^{5}$

Segundo as entrevistadas, é a mulher que incomoda-se ao ver a casa suja e desorganizada, é ela que perturba-se ao questionar sobre como está a vida escolar dos filhos e é ela também que, "naturalmente", ocupa-se da casa. O homem, ao que parece, não se deixa estremecer pelos cuidados de que o lar necessita: ao ter passado todo o dia preocupado com o espaço público - em que pode ser valorizado pelo seu trabalho - pouca importância dará ao ambiente privado, marcado pela falta de valor e de reconhecimento.

Os relatos revelam que esta é a ordem a que as entrevistadas e os pais de seus filhos/filhas submeteram-se: a elas também cabe a conquista de um emprego formal, desde que mantenham a casa da maneira como delas é esperado; ao pai, porém, é imprescindível que se ocupe do sustento da família, sendo que esta cobrança é efetuada pela sociedade, pelo sistema familiar e também pelos próprios homens. Portanto, prover o sustento da casa aparece ainda como a principal atribuição do pai, pois ainda que a mulher possa trabalhar remuneradamente, contribuindo para o orçamento doméstico, "cabe ao homem ganhar maior salário a fim de se incumbir de sua função de chefe" (SAFFIOTI, 1987, p. 24).

\footnotetext{
${ }^{5}$ Sobre estes aspectos, cabe ressaltar que a mulheres entrevistadas, em sua maioria, eram donas de casa, com baixa escolaridade e pertencentes a classes populares, o que, assim como o aspecto explicitado na nota anterior, acarreta em um viés específico à pesquisa. Embora este contexto social não tenha sido objeto de análise neste estudo, destaca-se que os relatos produzidos por este grupo podem diferir significativamente de outras experiências contemporâneas de maternidade e paternidade.
} 
Ficando delegadas ao homem as atividades do espaço público, cabe à mulher ocupar-se com a manutenção do mundo privado. Ao incumbir-se das tarefas domésticas, que se caracterizam pela repetição das atividades e não pela produção de algo que lhe pareça concreto, algumas vezes é dificultado à mulher o ingresso na vida pública, fazendo-a sentir-se não confirmada em seus desejos. Para a quarta entrevistada, a não assunção das responsabilidades pela casa de forma equilibrada por todos os membros da família faz com que ela deixe de lado o desejo de, como afirma a mesma, "trabalhar num outro trabalho". Segundo ela,

eu queria trabalhar num outro trabalho, sair fora de casa, não ficar em casa. Trabalhar numa loja, conviver com outras pessoas, não só com a família, porque eu convivo mais com a minha família. Eu quase não saio de casa, e eu gosto de participar de muitas coisas, assim, cursinho, essas coisas. (E4).

Nesta situação, a entrevistada não vê como possibilidade outro arranjo para a organização de sua vida diária que não seja aquele em que ela é a principal responsável pela manutenção da ordem do lar. Compreendendo que deve aceitar esta construção tradicional de mulher, priva-se de realizar-se em outros perfis, ou seja, de desenvolver, por exemplo, o lado profissional de sua vida. Retalhada em uma parte de seu ser, sente-se incompleta e não realizada, presa no hiato que existe entre o "determinismo" e o "desejo de ser", o que a faz sofrer.

Esta mesma entrevistada, quando perguntada sobre o que lhe impede de procurar um emprego, relatou que é o fato "de deixar a casa, porque daí não tem quem faça o trabalho de casa, daí eu não venço fazer lá fora, digamos, e... não tenho mais pique pra isso, e fazer em casa" (E4), novamente denunciando sentir-se destinada "naturalmente" a esta única possibilidade. A opção de conquistar espaço no mundo público só será uma opção se não "atrapalhar" os cuidados que deve ter com a casa, que são as obrigações destinadas à mulher.

A educação dos filhos, por fazer parte das questões relacionadas ao espaço privado, também fica sob responsabilidade da mulher. Este aspecto aparece nas falas das entrevistadas, por exemplo, quando a quinta entrevistada diz: "pai para os meus filhos... na realidade ele deixa a decisão mais por minha conta. Quem toma a decisão sou eu".

Haveria, dessa forma, uma explicação a priori para a diferença existente entre a maneira como a mulher assume a responsabilidade pelos filhos da maneira como o pai o faz. Isso porque seus relatos são taxativos ao denunciarem que "pra eles tanto faz" e "mãe chega e logo fala". Essas diferenças são compreendidas como de "ordem natural", como se pais e mães se constituíssem desta forma porque essas são as características gerais dessas experiências. Ser pai e ser mãe não passa, para estas mulheres, pelo processo de singularização: elas mantêm-se na generalidade dos corpos, ou seja, subjetivamente permanecem presas àquilo que "biologicamente estariam destinadas", não contendo a impressão das marcas da apropriação singular que cada ser humano pode realizar sendo corpo/consciência, tornando a construção de seus perfis cabíveis para os seus projetos de vida como seres únicos que são.

Aparece também nesta discussão a diferenciação que se faz do contato entre pais/mães e filhos. Em suas vivências de parentalidade, é a mãe que experimenta o contato físico com os filhos, iniciado e por isso facilitado pela gestação e pela amamentação. É ela também que estabelece as trocas afetivas de forma mais explícita, através de abraços e beijos, deixando transparecer o "amor de mãe", para elas mais natural do que o "amor de pai".

Estas diferenças podem ser pensadas a partir dos modelos de gênero que estão postos na sociedade e que foram construídos ao longo da história. Segundo Safiotti $(1987$, p. 25) "o homem será considerado macho na medida em que for capaz de disfarçar, inibir, sufocar seus sentimentos. A educação de um verdadeiro macho inclui necessariamente a famosa ordem: 'Homem (com H maiúsculo) não chora"”. Neste sentido, para a primeira entrevistada, "eu sou mais próxima com os filhos. Quando o mais velho nasceu ele tinha medo de pegar, ele não beijava o filho porque ele era filho homem. Homem não pode beijar homem".

Os laços de proximidade afetiva, somados às questões da assunção desigual das responsabilidades com a casa e com os filhos - ainda que nos relatos apareça uma tentativa de o homem incluir-se nesses cuidados - apontam para a permanência dos modelos tradicionais da mãe que cuida e do pai que provê. Segundo Toneli (2006, p. 267)

o que se pode depreender de toda essa discussão é que a paternidade ainda é definida como sinônimo de prover e proteger, embora inclua, contemporaneamente, comportamentos de cuidados nas rotinas diárias dos pais e contatos físicos mais próximos, em especial quando os filhos são pequenos. No entanto, os cuidados mantêmse fortemente associados à mãe. Responsabilidades atribuídas a pais e mães, ainda que existam mudanças nas práticas sociais em curso, continuam distintas [...] Assim, a masculinidade pode comportar dimensões da feminilidade na paternidade, como cuidar dos filhos; mas não comporta o pai não ser provedor.

A educação recebida pelas mulheres entrevistadas aparece também como reforçadora dos modelos tradicionais de gênero, denunciada numa das falas: "quando eu era criança, fui criada, a minha mãe e o meu pai criaram a gente pra ter uma família, crescer, casar, ter filhos" (E5). Dessa forma, desde muito cedo, à menina é ensinado que para que se torne mulher deve adquirir a capacidade de receber o amor de um homem e de formar uma família. É este o seu destino. É a condição de existir para outro que imprimirá à sua existência um significado. Para cumprir seu destino de mulher, deverá casar-se e ter muitos filhos, colocando na centralidade de sua vida a manutenção do lar que deve erigir; outras escolhas só se tornarão possíveis se esta primeira condição tiver sido satisfeita (BEAUVOIR, 1980). 
Dessa forma, a realidade concreta em que a mulher se constitui caracteriza-se pela permanência de mitos sobre o feminino, em que não haverá como sustentar outro espaço para ela a não ser aquele já designado, pois se entende "a verdadeira mulher" como aquela que cumpre seu destino posto de mulher-mãe. Por outro lado, ao homem também são impostas condições para que possa estabelecer outras relações de paternidade, que possibilitem superar o modelo tradicional: somente após garantir a provisão da casa, poderá estabelecer outras formas de relação com os filhos, em que possam estar presentes outros aspectos como afetividade, responsabilidade, dedicação, interação.

\section{Sofrimento}

A partir da perspectiva de que o sofrimento está relacionado, especialmente, à forma como os indivíduos conduzem suas vidas e suas relações, as falas das entrevistadas chamam atenção para o fato de a maternidade, em muitos momentos, ter-se tornado um fator gerador de sofrimento em função, principalmente, das dificuldades consideradas por elas como provenientes desta experiência.

Embora as denúncias sobre o sofrimento tenham aparecido ao longo de toda a pesquisa, diluídas nas quatro categorias separadas aqui com a finalidade de facilitar a análise do conteúdo das falas, destacam-se os pontos em que esta experiência de sofrimento é expressa pontualmente, como resposta às questões voltadas às dificuldades enfrentadas nestas vivências. Durante o grupo focal, por exemplo, uma das mulheres relatou "eu imaginava ser mãe diferente. Achava que só existia felicidade, só alegria. E depois que eu fui mãe que eu fui ver que é totalmente diferente daquilo que a gente imagina. Tem muitas alegrias, mas tem também muitas preocupações".

Outros momentos de sofrimento relacionados à maternidade foram descritos como de sacrifício, responsabilidades, preocupações e abdicação de seu desejo em função do desejo do outro. Este último aspecto apareceu denunciado na fala de uma das mulheres participantes do grupo focal : "esqueci de mim pelos filhos". Outra entrevistada chega a relacionar a maternidade diretamente ao sofrimento: "dizem que ser mãe é sofrer no paraíso. Para mim, ser mãe, é sofrer num inferno mesmo" e, mais tarde, "então a maternidade também, pra mim, foi um sofrimento". Também a rotina que o "ser mãe" implica à mulher a sobrecarrega e a faz sentir-se esgotada.

O sofrimento pode ser entendido a partir das dificuldades que as mulheres enfrentam em seu dia a dia nas suas relações com os filhos e também com seus companheiros. As principais dificuldades relatadas pelas mulheres com relação à educação dos filhos referem-se à gradativa independência dos mesmos com relação aos seus cuidados. Ver os filhos desejarem por si próprios, não atendendo mais aos desejos da mãe, é o início de um rompimento vivenciado com muito pesar.

Neste sentido, quando crianças, os filhos ainda dependem da mãe para tudo; ela é, assim, confirmada como essencial, aquela que garante o crescimento e o desenvolvimento de outro ser. A mulher faz, assim, da tarefa de auxiliar o outro a sua principal fonte de prazer e satisfação; seu maior desejo é o desejo de seu filho/ filha e ela busca realizar-se através das conquistas que ele alcança. O sofrimento aparece, então, no momento em que os projetos que desejou para o outro começam a ser concretizados e a mulher se dá conta de que deles não faz parte como gostaria. O filho mostra-se como alguém que deseja algo diferente do desejo dela e, nesse sentido, ela tende a tornar-se o "não essencial", conforme discutiu Beauvoir (1949).

A idade dos filhos também foi referida, nos relatos das entrevistadas, como uma dificuldade vivenciada em seu cotidiano. A idade demarca não só que os filhos cresceram e que, na medida em que o tempo passa, tornam-se autônomos e não mais dependentes de sua dedicação integral, mas também traz dificuldades de impor limites a esse ser que agora deseja, fazendo com que não sigam as decisões dos pais.

Por meio dos relatos foi possível perceber que as dificuldades vividas pelas mulheres entrevistadas nas relações que estabeleciam com seus filhos em seu dia a dia eram compreendidas como geradoras de sofrimento - o que, de alguma forma, as levou a buscar os serviços prestados pela psicologia - como exposto a seguir.

\section{Espaço para diálogo}

Quando perguntadas sobre o motivo do encaminhamento ou busca espontânea pelos serviços prestados pela psicologia por meio do Projeto de Extensão de Saúde Mental, todas as entrevistadas disseram que ela estava relacionada às suas experiências de maternidade e paternidade. Em alguns casos, as mulheres chegaram até o grupo não por dificuldades de relacionamento com os filhos, mas para tentar resolver problemas que os mesmos estavam enfrentando naquele momento de suas vidas.

Dessa forma, buscando soluções para os problemas do outro, as mulheres acabaram encontrando ajuda para si, já que permaneceram no grupo e puderam encontrar algum apoio. Ao perceberem que para ajudar o outro era preciso, antes, ajudarem a si próprias, sua permanência esteve relacionada à percepção de que elas mesmas poderiam, naquele espaço, encontrar orientação na busca por respostas às dificuldades vivenciadas nas experiências de maternidade e paternidade.

As entrevistadas relataram, ainda, que possuíam poucas oportunidades efetivas para a discussão de dúvidas e questionamentos sobre as dificuldades enfrentadas cotidianamente, em qualquer relação que estabeleciam. Neste sentido, o grupo se apresentou como uma possibilidade de espaço para reflexão e compartilhamento de incertezas quanto à vivência da maternidade e da paternidade. A partir de seus relatos, portanto, ficou clara a importância e influência que o espaço para o diálogo sobre as experiências da maternidade e da paternidade das entrevistadas têm no enfrentamento dos percalços a elas relacionadas e do sofrimento causado pelos problemas enfrentados nessas relações.

Fractal, Rev. Psicol., v. 27 - n. 2, p. 130-138, 2015 


\section{Considerações finais}

Por todas as reflexões proporcionadas por esta pesquisa, tem-se que as experiências de maternidade e paternidade constituem-se como fundamentais para a construção que o ser humano faz do significado de sua vida e, por isso, a maneira como estas experiências serão organizadas proporcionará a cada sujeito diferentes vivências afetivas, inclusive de bem-estar ou de sofrimento. A partir disto, destaca-se a importância do estudo sobre os temas da maternidade e da paternidade, bem como de suas relações com o sofrimento, através de outras pesquisas, tanto pela ciência psicológica como para áreas afins.

Para as mulheres entrevistadas, o sofrimento apareceu relacionado principalmente ao determinismo das experiências da maternidade e da paternidade, a algo que está "fora" do sujeito, um padrão, uma norma, mas que é colocado por elas mesmas como algo que "deve ser" buscado, atingido. Neste sentido, pode-se refletir que, na medida em que novas formas de experiência e de construção da maternidade e da paternidade não signifiquem "pequenas revoluções individuais", ou seja, não impliquem movimentos do próprio sujeito, qualquer que sejam as possibilidades colocadas social e coletivamente - mesmo as "novas formas de paternidade" -, poderão causar sofrimento. Isto ocorre na medida em que o sujeito continue a vivenciar estas experiências enquanto um "dever ser", ou seja, como um novo determinismo, mantendo-os em processos de alienação, como apontado pela teoria existencialista sartreana.

Dessa forma, o Projeto de Extensão em Saúde Mental, ao organizar espaços grupais para o exercício de reflexões, permitiu que o trabalho realizado pela Psicologia neste campo tenha sido fonte de informação e oportunidade de construção de medidas alternativas na busca da qualidade de vida das pessoas participantes. Isto ocorreu na medida em que o espaço grupal representou mediação para a vivência de novos vínculos relacionais e para a capacidade de reorganizar as experiências daquelas mulheres, de forma a atribuir-lhes novos significados, incluindo-se, neste âmbito, as experiências relacionadas à maternidade e à paternidade. Os efeitos produzidos por este modo de atuação são, portanto, fenômenos a serem considerados pelos serviços de saúde para a organização e planejamento dos atendimentos prestados à população, na medida em que apontam para possibilidades de intervenção por parte dos profissionais visando prevenção de sofrimento e promoção de saúde.

\section{Referências}

ARIÈS, P. História social da criança e da família. 2. ed. Rio de Janeiro: LTC, 1981.

BEAUVOIR, S. de. O segundo sexo: fatos e mitos. São Paulo: Círculo do Livro, 1949. v. 1.

BEAUVOIR, S. O segundo sexo: a experiência vivida. Rio de Janeiro: Nova Fronteira, 1980. v. 2.

BRAGA, M. da G. R.; AMAZONAS, M. C. L. de A. Família: maternidade e procriação assistida. Psicologia em Estudo, [S.1.], v. 10, n. 1, p. 11-18, jan./abr. 2005
BOCK, A. M. B. Psicologia e compromisso social. São Paulo: Cortez, 2003.

COSTA, R. G. Reprodução e gênero: paternidades, masculinidades e teorias da concepção. Revista Estudos Feministas, Florianópolis, v. 10, n. 2, p. 339-356, 2002.

KAHHALE, E. M. P. Psicologia na saúde: em busca de uma leitura crítica e uma atuação compromissada. In: BOCK, A. M. B. (Org.). A perspectiva sócio-história na formação em Psicologia. Petrópolis, RJ: Vozes, 2003. p. 161- 191.

LOURO, G. L. Pedagogias da sexualidade. In: PEDRO, J. M.; GROSSI, M. P. (Org.). Masculino, feminino, plural: gênero na interdisciplinaridade. Florianópolis: Mulheres, 1998. p. 9-33.

MAHEIRIE, K.; PRETTO, Z. Contribuição do movimento progressivo-regressivo sartreano para a Psicologia. Revista do Departamento de Psicologia - UFF, Niterói, v. 19, n. 2, p. 455462, jul./dez. 2007.

MINAYO, M. C. de S. O desafio do conhecimento: pesquisa qualitativa em saúde. São Paulo: Hucitec, 2008.

PÁDUA, E. M. M. de. Metodologia de pesquisa: abordagem teórico-prática. 10. ed. rev. e atual. Campinas, SP: Papirus, 2005.

PICCININI, C. A.; SILVA, M. da R. Sentimentos sobre a paternidade e o envolvimento paterno: um estudo qualitativo. Estudos de Psicologia, Campinas, v. 24, n. 4, p. 561-573, out./ dez. 2007.

PRETTO, Z. Como tecer a mais antiga/contemporânea trama: significações de amor segundo homens jovens universitários. 2003. Dissertação (Mestrado)-Programa de Pós-Graduação em Psicologia da Universidade Federal de Santa Catarina, Florianópolis, 2003.

RAGO, M. Epistemologia feminista, gênero e história. In: PEDRO, J. M.; GROSSI, M. P. (Org.). Masculino, feminino, plural: gênero na interdisciplinaridade. Florianópolis: Mulheres, 1998. p. 20- 41

SAFFIOTI, H. I. B. O poder do macho. São Paulo: Moderna, 1987.

SANDRI, G. A constituição do sujeito nas relações de gênero: considerações a partir da perspectiva histórico-cultural. Contra Pontos, Itajaí - SC, ano 1, n. 2, p. 37-44, 2001.

SARTRE, J-P. Questão de método. São Paulo: Abril Cultural, 1978a.

SARTRE, J-P. O Existencialismo é um humanismo. São Paulo: Abril Cultural, 1978b.

SARTRE, J.-P. O ser e o nada. 14. ed. Petrópolis, RJ: Vozes, 1997.

SCHNEIDER, D. R. Liberdade e dinâmica psicológica em Sartre. Natureza Humana, [S.1.], v. 8, n. 2, p. 283-314, 2006.

SCHNEIDER, D. R. Sartre e a psicologia clínica. Florianópolis: UFSC, 2011.

SCOTT, J. Gênero: uma categoria útil de análise histórica. Educação e Realidade, Porto Alegre, v. 16, n. 2, p. 5-22, jul./ dez. 1990.

SOARES, J. dos S.; CARVALHO, A. M. Mulher e mãe, "novos papéis", velhas exigências: experiência de psicoterapia breve grupal. Psicologia em Estudo, [S.1.], v. 8, n. spe., p. 39-44, 2003. 
TONELI, M. J. F. Paternidade em contextos urbanos: entre o dever e o prazer. In: MINELLA, L. S.; FUNCK, S. B. (Org.). Saberes e fazeres de gênero: entre o local e o global. Florianópolis: UFSC, 2006. p. 257-270.

Recebido em: 22 de abril de 2010

Aceito em: 3 de dezembro de 2014 